\title{
Ensino superior, ecologia de saberes e presença indígena na Universidade pública: uma proposta de pesquisa ${ }^{1}$
}

\section{Educación superior, ecología del conocimiento y presencia indígena em la universidad pública: una propuesta de investigacion
Higher education, ecology of knowledge and indigenous presence in the public university: a research proposal

\section{Dra. Célia Maria Foster Silvestre ${ }^{2}$}

\begin{abstract}
Resumo
As Ciências Humanas e Sociais constituem campo privilegiado para refletir a respeito da produção do conhecimento, suas características e efeitos na sociedade mais ampla. Nessa linha, as universidades são lócus de produção de uma forma específica de conhecimento, o científico, que, historicamente, caracterizou-se por ser restrito à elite, dando dimensão de universal para um saber ocidental e moderno. Nesse sentido, excluiu coletivos portadores de conhecimentos relevantes, dando-os como inexistentes. No Brasil, as políticas públicas contribuíram, nos últimos anos, para mudar o perfil da universidade, incluindo coletivos historicamente dela excluídos. Paradoxalmente, do ponto de vista político, esse tem sido um elemento que vem atraindo críticas à universidade pública, que passou a ser questionada em sua relevância social e competência na produção de conhecimento. $\mathrm{O}$ artigo apresenta reflexões pertinentes a um projeto de pesquisa que propõe uma análise do processo de expansão da universidade pública no Brasil, especialmente no que se refere à ampliação das políticas de acesso à universidade e, de forma específica, situando esse aspecto na Universidade Estadual de Mato Grosso do Sul, UEMS, focando no acesso dos coletivos indígenas à universidade. A pergunta de fundo para a pesquisa se refere às relações provocadas pelas presenças desses coletivos, quais são os efeitos para a promoção de uma ecologia de saberes e quais são as políticas, experiências, projetos, metodologias, vivências nesse sentido. A metodologia consiste em uma abordagem etnográfica, considerando o envolvimento da equipe de pesquisa no campo onde ela ocorre, interdisciplinar, qualitativa, bibliográfica e documental, a partir de dados das coordenadorias e outras instâncias administrativas na universidade, eventos e documentos públicos produzidos por estudantes indígenas.
\end{abstract}

Palavras-chave: Ensino superior, ecologia de saberes, políticas públicas de acesso à universidade.

\section{Resumen}

\footnotetext{
${ }^{1}$ Artigo apresentado no II Congresso Internacional Online de Estudos sobre Culturas, na modalidade online, 2020.

${ }^{2}$ Doutora em Ciências Sociais. Universidade Estadual de Mato Grosso do Sul. Ciências Sociais/ProfHistória, Amambai. PPGAnt, UFGD. CLAEC. Amambai/Dourados, MS. celia.silvestre@ gmail.com.
} 
Las ciencias humanas y sociales son un campo privilegiado para reflexionar sobre la producción de conocimiento, sus características y efectos en la sociedad en general. En este sentido, las universidades son el lugar de producción de una forma específica de conocimiento, el científico, que históricamente se caracterizó por estar restringido a la élite, dando la dimensión del conocimiento universal al occidental y moderno. En este sentido, excluyó a los colectivos con conocimiento relevante, dándolos como inexistentes. En Brasil, las políticas públicas han contribuido en los últimos años a cambiar el perfil de la universidad, incluidos los colectivos históricamente excluidos de ella. Paradójicamente, desde un punto de vista político, este ha sido un elemento que ha suscitado críticas por parte de la universidad pública, que ha sido cuestionada por su relevancia social y competencia en la producción de conocimiento. El artículo presenta reflexiones pertinentes a un proyecto de investigación que propone un análisis del proceso de expansión de la universidad pública en Brasil, especialmente con respecto a la expansión de las políticas de acceso a la universidad y, específicamente, ubicar este aspecto en la Universidad Estatal de Mato Grosso do Sul, UEMS, centrándose en el acceso de los grupos indígenas a la universidad. La pregunta básica para la investigación se refiere a las relaciones causadas por la presencia de estos colectivos, cuáles son los efectos para la promoción de una ecología del conocimiento y cuáles son las políticas, experiencias, proyectos, metodologías, experiencias en este sentido. La metodología consiste en un enfoque etnográfico, considerando la participación del equipo de investigación en el campo donde ocurre, interdisciplinaria, cualitativa, bibliográfica y documental, basada en datos de los coordinadores y otros organismos administrativos de la universidad, eventos y documentos públicos producidos por estudiantes indígenas.

Palabras clave: Educación superior, ecología del conocimiento, políticas públicas de acceso a la universidad.

\begin{abstract}
Human and Social Sciences are a privileged field to reflect on the production of knowledge, its characteristics and effects on the wider society. Along these lines, universities are the locus of production of a specific form of knowledge, the scientific, which, historically, was characterized by being restricted to the elite, giving the dimension of universal to western and modern knowledge. In this sense, it excluded collectives with relevant knowledge, giving them as non-existent. In Brazil, public policies have contributed, in recent years, to changing the profile of the university, including collectives historically excluded from it. Paradoxically, from a political point of view, this has been an element that has attracted criticism from the public university, which has come to be questioned on its social relevance and competence in the production of knowledge. The paper presents reflections pertinent to a research project that proposes an analysis of the expansion process of the public university in Brazil, especially with regard to the expansion of access policies to the university, and specifically, placing this aspect at the State University of Mato Grosso do Sul, UEMS, focusing on the access of indigenous groups to the university. The basic question for the research refers to the relationships caused by the presence of these collectives, what are the effects for the promotion of an ecology of knowledge and what are the policies, experiences, projects, methodologies, experiences in this sense. The methodology consists of an ethnographic approach, considering the involvement of the research team in the field where it occurs, interdisciplinary,
\end{abstract}


qualitative, bibliographic and documentary, based on data from the coordinators and other administrative bodies at the university, public events and documents produced by indigenous students.

Keywords: Higher education, ecology of knowledge, public policies for access to university.

\section{A dimensão do problema, relevância da pesquisa e objetivos}

Quando niño me encantaba pisar las huellas que otros dejaban en la arena. Unas veces, la mayoria, mis pies encajaban holgadamente dentro de pisadas ajenas. Otras, no. En el primer caso, mi huella no existía. Y sin ella, tampoco yo. Era como jugar a fantasmas. En el segundo, desfiguraba las huellas de otros com las mías. Y nadie podia demostrar que caminé por la playa. El fantasma de antes se había transformado en un monstruo de pies deformes. Dos pruebas y dos mentiras. La única verdad era lo único indemostrable: sólo yo estuve em la playa... Un ser mitad fantasma, mitad monstruo.

(MANUEL, 2010, s/p)

A universidade pública brasileira passa, atualmente, por ataques de ordem política, que se reflete na negação do lugar social e competência dessa instituição, seus pesquisadores e pesquisadoras, servidores e servidoras, discentes, com consequências para seu orçamento e legitimidade diante da sociedade. Uma das formas de ataque é a redução de políticas públicas que favorece o acesso e permanência de integrantes de coletivos até então dela excluídos. Entendemos que esse momento histórico está relacionado às mudanças de paradigmas que, ao mesmo tempo que colocou brechas para a crítica à ciência ocidental e moderna, favoreceu a democratização do ensino superior, o que subverte relações de poder socialmente arraigadas.

Esse artigo apresenta uma proposta de pesquisa que tem a intenção de levantar subsídios que contribuam para evidenciar o histórico da universidade, olhando para a ampliação das universidades públicas no Brasil e os efeitos para os setores dela incluídos, especialmente a partir da presença de novos conhecimentos. Para isso, se vale da presença dos estudantes indígenas na Universidade Estadual de Mato Grosso do Sul, que nos coloca desafios, tanto do ponto de vista epistemológico/metodológico, quanto das políticas públicas.

A proposta enseja reunir pesquisadores e pesquisadoras que vêm trabalhando com essas temáticas e coletivos; nesse sentido, favorece a produção, sistematização e divulgação dessas produções, fortalecendo as percepções de forma individual e coletiva, permitindo o compartilhamento dessas informações ente o coletivo e a universidade de forma mais ampla e contribuindo para a defesa da universidade pública, a validade dos conhecimentos e coletivos nela presente, e das ciências humanas e sociais.

\subsection{Dos objetivos}


A partir das referências e pressupostos teóricos aqui apresentados, tendo como fundamento o histórico de ampliação das Universidades Públicas no Brasil, o objetivo geral é pesquisar, analisar e descrever os contornos das políticas de acesso e permanência ao e no ensino superior de forma geral e em específico na Universidade Estadual de Mato Grosso do Sul (UEMS), assim como suas características e especificidades, considerando como recorte temporal seu início a partir de 2002, as políticas e projetos que promovem o acolhimento de estudantes indígenas na UEMS e as conexões dessas formações com seus coletivos e as aldeias que habitam, visando contribuir para tradução de conhecimentos e uma ecologia de saberes.

De forma específica, pretendemos: investigar relação das Ciências Sociais com os contextos históricos; explicitar os contornos e aspectos teóricos da virada epistemológica nas Ciências Sociais; investigar o cenário histórico de ampliação das Universidades Públicas no Brasil; enunciar o arcabouço e proposta teórica das Epistemologias do Sul como parâmetro para repensar a produção de conhecimentos descoloniais, na perspectiva de diálogos sul-sul; aproximar essa análise do cenário das Ciências Sociais em Mato Grosso do Sul; refletir a respeito dos aspectos políticos e pedagógicos expressos em documentos, deliberações e projetos de curso de graduação, assim como ações de ensino, pesquisa e extensão em razão da presença dos estudantes kaiowá e guarani; analisar as agências desses estudantes, organizados enquanto coletivo na Universidade e suas referências mais amplas para a produção de demandas, a partir das atividades que desenvolvem; a partir de suas presenças, trajetórias e ações na Universidade, investigar as relações que estabelecem, entre si, com os demais estudantes, no nível institucional, didático e como contribuem para a criação de uma ecologia de saberes.

\section{As Ciências Sociais e a universidade pública no Brasil}

E quem vai perceber essa sabedoria dos periféricos? Quem vai chegar até esse ponto de humildade? Quando a elite está condicionada pela sua própria superioridade Quem vai ter peito para encarar a dificuldade de uma pessoa sem universidade? Quem vai querer largar as teorias para abraçar as utopias? As utopias das vivências e da sabedoria

Quem vai largar as teorias que geram facilmente arrogância? Para abraçar a humildade intrínseca onde há sabedoria e esperança ${ }^{3}$

\footnotetext{
${ }^{3}$ Disparem sobre a utopista! Resumo poético da Aula Magistral do Professor Boaventura de Sousa Santos proferida a 22 de abril de 2016, em Coimbra, Portugal. Disponível em https://journals.openedition.org/rccs/6852. Acesso em 06 de fevereiro de 2020.
} 
No Brasil, as políticas públicas para o acesso e permanência de estudantes em universidades, sejam elas públicas ou particulares, tiveram um período de expansão, no Brasil, especialmente até o ano de 2016, tanto no que se refere à implantação de novas universidades públicas e consequente aumento de número de vagas, quanto à implantação de cotas étnicas e sociais, programas de financiamento da educação superior em instituições privadas e bolsas visando custeio de ações de formação e permanência estudantil. Essas políticas, no Brasil, contribuíram para democratizar o acesso ao ensino superior , mudando o perfil da universidade, inserindo grupos sociais até então dela alijados (CORTES, LIMA, 2016).

Em pesquisa realizada no curso de Ciências Sociais, Universidade Estadual de Mato Grosso do Sul, UEMS, Unidade de Ensino Superior de Amambai, em 2017, o resultado apontava para a seguinte configuração: estudantes oriundos de famílias pobres, ingresso majoritário de estudantes indígenas, para além da porcentagem de cotas e a manifestação, por parte dos estudantes, do impacto positivo dessas políticas para suas permanências (SILVESTRE, LIMA, 2017).

A pesquisa citada buscou se valer de um campo propício para esses questionamento: considerando as políticas públicas para o acesso e permanência no ensino superior, a presença de jovens oriundos de classes subalternas e integrantes de coletivos indígenas, o escopo de formação próprio das Ciências Sociais, buscando entender tanto o impacto produzido por essas políticas e seu lugar na vida dos estudantes, quanto ao nível de reconhecimento, de si e do contexto social, por parte dos estudantes em Ciências Sociais. Para além desses objetivos imediatos, tinha a intenção de perceber se esse re-conhecimento produziria potenciais de transformação, tanto individuais quanto coletivos, investigando quais eram os projetos nos quais os jovens estavam engajados.

É importante mencionar, ainda, que as Ciências Sociais são campo fecundo para esse tipo de análise, considerando que as políticas públicas não surgem aleatoriamente nos programas de governo e que existe uma relação intrínseca entre sua emergência e a ação política dos coletivos que as demandam (CORTES, LIMA, 2016).

Menos de quatro anos se passaram do momento de proposição dessa pesquisa, em 2016. Em um cenário de garantia de direitos e reconhecimento das Ciências Humanas, a validade de produzir conhecimento a respeito do assunto, incluindo a abordagem proposta, estava implícita. Em 2020 há um novo cenário no que se refere às políticas públicas no Brasil, principalmente para a educação: as Ciências Sociais passaram a ser sistematicamente 
deslegitimadas enquanto campo de análise e conhecimento socialmente relevante. Não é necessário apontar referência, aqui. É de conhecimento público, notório e internacional.

Entretanto, integrantes das classes subalternas e diferentes origens étnicas continuam na universidade, que passou a ser território ocupado por jovens pretas e pretas, indígenas, pobres, mulheres. Portanto, esses coletivos continuam demandando as políticas públicas enquanto expressão materializada das lutas por direitos e, ao mesmo tempo, trazendo para ela suas experiências de vida, seus conhecimentos, e projeções.

No que se refere à presença dos coletivos indígenas, a UEMS é a universidade que mais recebe estudantes indígenas em Mato Grosso do Sul, dada sua presença em vários municípios no estado e disponibilidade de vagas no sistema de cotas (BROSTOLIN, CRUZ, 2010). A localização geográfica das Unidades de Ensino Superior e a proximidade com as aldeias indica a condição estratégica potencial dessa universidade na formação desses e dessas jovens.

Em pesquisa que procurou analisar a presença de estudantes kaiowá e guarani na UEMS, Unidade de Amambai, em uma perspectiva de gênero, apontou-se para o crescente ingresso de integrantes dessa etnia, para as expectativas pessoais e familiares, os desafios relacionados à permanência e para as mudanças de cunho pessoal e social a partir da vida na universidade (SILVESTRE, VILLAFAN VIERA, 2016).

Esses elementos são aqui expressos no sentido de dimensionar uma trajetória de pesquisa e da práxis que lhe é inerente. Eles constituem o que Boaventura de Sousa Santos caracteriza como artesania nas Ciências Sociais, que traz em si um desafio e um comprometimento, que se trata de pensar em políticas, programas, projetos, a partir da universidade, para além do colonialismo. O processo de artesania nas Ciências Sociais é constituído por um conhecimento engajado, para o qual ocorrem os diversos coletivos, saberes e metodologias (SANTOS, 2018).

Portanto, para além do conhecimento engajado, a artesania nas Ciências Sociais aponta para a multiplicidade de saberes/conhecimentos que compõem o conhecimento social, e convida a olharmos para além dos pressupostos que fundamentaram a auto atribuída primazia ocidental, o que requer uma abordagem multidisciplinar.

As Ciências Sociais surgiram no contexto da sociedade industrial, na Europa, como área de conhecimento voltada para refletir a respeito do impacto das mudanças sociais promovidas pela novas formas de produção capitalista. Ainda que a Filosofia também se dedique a entender o humano em suas múltiplas dimensões, essas abordagens, segundo os 
ditames científicos, se davam no nível do dever ser. As Ciências Sociais instauram problemas de pesquisa, definem metodologias e escopos teóricos.

No contexto do surgimento do pensamento científico, que no bojo do iluminismo passa a ganhar cada vez maior prestígio, o pensamento social se caracterizou, historicamente, como forma de conhecimento relacionado aos pressupostos da modernidade, formulando seu escopo teórico em torno das categorias e relações sociais ocidentais, especialmente a sociedade industrial e o mundo do trabalho. Neste sentido, o pensamento social contém, em sua origem, os fundamentos históricos sociais que o constitui (LÖWY, 1987, 2014).

Esse pensamento surge, portanto, bastante vinculado às metodologias próprias das ciências biológicas, que têm a primazia em termos de prestígio e define-se no método positivista (a partir do cartesianismo e do empirismo); se funda na separação ente homem e natureza e na submissão dessa, àquele.

No que se refere ao materialismo histórico, com a reflexão que busca enunciar parâmetros para a transformação das relações econômicas e políticas se coloca a problemática emergencial da transformação das relação de produção e, a partir dela, a emancipação da classe trabalhadora e modificação da superestrutura.

Ao dimensionar essa origem das Ciências Sociais e o prestígio do conhecimento científico, é possível estabelecer uma correlação entre o desenvolvimento da sociedade ocidental, suas instituições e as relações estabelecidas na civilização capitalista, como menciona Löwy (2013), e os paradigmas que orientam sua análise. A teoria social é fruto do seu tempo, mas a sociedade ocidental, da forma como se institui na modernidade, também é fruto das perspectivas que produzem as ciências sociais, em seus avanços e permanências, quer seja questionando ou reforçando suas matrizes.

Essa perspectiva não fornece a abertura para o reconhecimento da validade de formas de conhecimento outras. Por outro lado, é necessário recuar um passo desse momento da modernidade e reconhecer que pouco tempo separava a emergência das Ciências Sociais do período em que fogueiras reais era utilizadas para combater quem ousava ultrapassar os bem estabelecidos cânones religiosos e apresentar questões surgidas nas chamas de suas mentes, o que adquiriu a dimensão de uma verdadeira guerra no período inquisitorial. Essa guerra se expressa a partir do acesso restrito à educação (quem podia aprender), dos livros proibidos, a vigilância de leitura e das mentes a partir do dogma da confissão e da fiscalização nas relações mais cotidianas, criminalização, tortura, confinamento e morte dos infratores. Pensemos em Menocchio, o moleiro do século XVI que Ginzburg nos apresenta em $O$ queijo 
e os vermes e suas hipóteses para o surgimento da vida, urdidas no contexto em que ele próprio vivia (GINZBURG, 2006).

Trazer Ginzburg (2006) para a reflexão implica em considerar a emergência de novas metodologias de pesquisa, que visem dar conta das lutas desiguais entre o conhecimento hegemônico e aquele que brota das camadas populares, dando a conhecer esse conhecimento tornado inviabilizado ao ser invisibilizado.

Ao refletirmos a esse respeito em termos temporais, temos, ainda, que pensar no efeito da coesão desses elementos em sua relação dialética com a expansão econômica e cultural europeia promovida pela colonização.

Fazer conexão entre o momento histórico e a produção de conhecimento consiste em uma estratégia que nos permita inserir alguns aspectos do qual emergirão as questões que pretendemos levantar para fundamentar os argumentos aqui expostos. Primeiro, em uma escala ampliada, permite dimensionar que a partir da década de setenta ocorre a reestruturação econômica e emergência de uma agenda política neoliberal, com consequências na produção do conhecimento, que se expressam em uma chamada "crise de paradigmas". Segundo, argumentar que novos problemas e sujeitos políticos emergem, no contexto de um mundo tecnológico, encolhido em sua relação espaço-temporal e expandido em sua dimensão globalizada (HARVEY, 1992). Terceiro, refletir que esse se torna o cenário da assim chamada pós-modernidade, no qual a noção de fixidez, própria da modernidade e das meta-teorias que nela emergem se perde, abrindo brecha para a dimensão dos conhecimentos locais (SANTOS, $2008)^{4}$.

Nesse sentido, surge uma gama de teorias a relacionar a ciência e a educação ao projeto colonizador, e essa crítica emerge muito fortemente na América Latina, mas também em outras regiões e países do sul global (SANTOS, (SANTOS, 2002, 2007, 2008, 2018a, 2018b; LANDER, 2005).

A questão que se coloca é, nessa sequência de argumentos, qual tem sido o locus da universidade nesse contexto de produção de conhecimento? No Brasil, a universidade foi criada a partir de um projeto eurocentrista, com uma produção de conhecimento que se vale dos referenciais teóricos europeus. No que se refere às Ciências Sociais, o currículo de formação das novas gerações segue fortemente centrado nesses referenciais. Entretanto, as

\footnotetext{
${ }^{4}$ Existe uma grande produção, tanto em termos quantitativos e de temas, de autores e autoras pós-modernos. Aqui, a observação busca, na condição de uma argumentação para um projeto de pesquisa, assinalar esse percurso e momento teórico-histórico e, portanto, autores e autoras não são trazidos para a discussão e citação bibliográfica.
} 
políticas de acesso à educação, nos últimos anos, mudaram o perfil da universidade, nela introduzindo integrantes/representantes de grupos até então ausentes, como discutiremos a partir de referenciais teóricos. A pergunta que parece pertinente exige voltar os olhos para o efeito dessas presenças para conhecimento produzido nas universidades brasileiras na área das Ciências Sociais e o impacto desse conhecimento na sociedade de forma mais ampla.

\section{Da metodologia}

A pesquisa proposta será desenvolvida a partir da combinação dos métodos quantitativos e qualitativos. Considerando a vinculação das pesquisadoras e pesquisadores na Universidade Estadual de Mato Grosso do Sul, parte da pesquisa será desenvolvida a partir do método etnográfico, que permite ao pesquisador enunciar o lugar do qual fala. Ao adotar essa abordagem, procura atentar para as experiências que não são visibilizadas, mas que produzem potenciais efeitos de transformação, enunciando o que Boaventura de Sousa Santos denomina de sociologia das emergências. Essa perspectiva se dará no sentido de compreender as iniciativas que promovem modificações nas relações de saber/poder e promovem uma ecologia de saberes, como forma de tradução intercultural e contra o desperdício da experiência. Experiência, aqui, se refere ao ser e estar no mundo em determinado tempo/espaço e a dimensão histórica e, portanto política, dessa vivência. (SANTOS, 2018).

Essa dimensão da pesquisa implica na observação da participação dos estudantes nos projetos de ensino e extensão, nas ações que desenvolvem na universidade, suas pautas e demandas. Implica em um olhar interessado e atento aos objetivos da pesquisa, pertinente à convivência com eles e elas em inúmeras situações pedagógicas e de sociabilidade acadêmica. Implica também na participação de eventos públicos nas aldeias para os quais docentes são frequentemente convidados, e na análise dos documentos finais oriundos desses momentos. De forma geral, implica no 'estar junto' e construir argumentos/saberes a partir dos lugares que ocupamos na universidade.

Além da observação, a pesquisa envolverá rodas de conversa com estudantes indígenas visando tratar dos temas relacionados aos desafios que enfrentam para estar universidade; seus anseios, percepções a respeito dela; suas narrativas a respeito das dificuldades com a linguagem, currículo, formas de socialidade; as expectativas que colocam a universidade como espaço/tempo para pensar a história de seu povo. Aqui, será possível utilizar desenhos, vídeos, escritas, música, teatro, para potencializar o fluxo de troca de 
conhecimentos. Para esses momentos de roda de conversa e outros de interação e interlocução direta com estudantes, será utilizado um termo de consentimento livre e esclarecido.

Nesse sentido, a pesquisa se constituirá em oportunidades para a produção de “... espaços colaborativos para o desenvolvimento do conhecimento, dentro dos quais o saber profissional dos investigadores se combina com o dos interessados locais para definir um problema a enfrentar" ( MARTIN, MADROÑAL, 2016, 269).

A metodologia utilizada visa criar, portanto, uma ambiente de colaboração para, a partir de uma realidade - nossas presenças na universidade pública brasileira, a presença dos estudantes indígenas na Unidade de Ensino Superior da UEMS de Amambai, Jardim e Dourados (MS), a grande porcentagem desses estudantes em Amambai (cerca de cinquenta por cento), possamos con-versar e refletir a respeito dessa realidade, reconhecendo-a como plural e, a partir dessa pluralidade, re-pensar os cânones das chamadas Humanidades e da universidade, promovendo a tradução e a ecologia de saberes. Trata-se, portanto, de uma metodologia para a produção de conhecimentos de orientação pública, comprometidos com os coletivos que atendemos, com as Humanidades e a universidade pública brasileira.

O termo "orientação pública", da forma como dele fazem uso Martin e Madroñal (2016), se refere a uma determinada forma de produção de conhecimento, com a utilização de metodologias descoloniais, diluição da linha entre teoria e aplicação, desfazimento de hierarquias no terreno de pesquisa, promoção de interlocução/tradução e produção de conhecimentos socialmente compartilhados.

A pesquisa bibliográfica será desenvolvida a partir das áreas teóricas de cada pesquisador e, para tanto, os objetivos específicos foram propostos a partir das experiências das pesquisadoras e pesquisadores em suas respectivas áreas.

Em alguns dos objetivos específicos se evidencia a necessidade da abordagem quantitativa, especialmente a respeito do acesso dos estudantes à UEMS a partir das políticas de acesso ao ensino superior, o que será desenvolvido a partir de dados numéricos disponíveis na Pró Reitoria de ensino da UEMS, coordenadoria de cursos e secretarias.

A análise documental se fará a partir dos projetos de curso cursos de graduação, PDI (Plano de Desenvolvimento Institucional) da UEMS e normatizações internas relacionadas ao assunto.

\section{Resultados esperados e considerações finais}

As Ciências Sociais devem, necessariamente, lidar com a o mundo vivido para além dos conceitos enquanto dispositivo de reflexão. É no bojo dos limites e potencialidades dados 
pelos conceitos que se produzem as narrativas que tanto analisam quanto limitam/potencializam as trans-for[m]ações. O escaneamento das palavras nos mostra as armadilhas do saber/fazer. Temos muitas palavras. Poucas delas fazem sentido para quem está em condição de silêncio ou na dis-posição do grito. As metodologias pautadas em conhecimentos e estéticas decoloniais contribuem para desvelar essas armadilhas e produzir performances para além dos lugares por onde se estabelecem essas teorias - o lugar da palavra, como lugar de certezas - explorando silêncios, vazios, ausências, promovendo rompantes e des - estabilizações. É nessa dimensão que produz e traz a potência da sociologia das ausências e sociologia das emergências, evidenciando outros modos de saber/fazer (SANTOS, 2018).

É neste sentido que pretende-se, com a pesquisa, a criação de espaços facilitadores da tradução intercultural e de produção de uma ecologia de saberes (SANTOS, 2018), a partir da presença dos Kaiowá e Guarani na universidade e do envolvimento com esses coletivos de forma mais ampla, que deverá resultar em novos olhares a respeito de suas contribuições para as vivências, práticas e os conhecimentos nela produzidos.

\section{Referências}

BROSTOLIN, M. R.; CRUZ, S. F. Educação e sustentabilidade: o porvir dos povos indígenas no ensino superior em Mato Grosso do Sul. Interações, Campo Grande, v. 11, n. 1, p. 33-42, jan./jun. 2010.

CORTES, Soraya Vargas; LIMA, Luciana Leite. A contribuição da sociologia para a análise de políticas públicas. Lua Nova [online]. 2012, n.87, pp.32- 62. ISSN 01026445. http://dx.doi.org/10.1590/S0102-64452012000300003. Acesso em 21 de abril de 2016.

GINZBURG, Carlo. O queijo e os vermes. São Paulo: Companhia das Letras, 2006.

HARVEY, David. A condição pós-moderna. 17. ed. [Trad. Adail Ubirajara Sobral; Maria Stela Gonçalves] São Paulo: Loyola, 1992.

LANDER, Edgardo. Ciências sociais: saberes coloniais e eurocêntricos. In: LANDER, Edgardo (Org). A colonialidade do saber: eurocentrismo e ciências sociais. Perspectivas latino-americanas. Sur Sur. Buenos Aires: CLACSO, 2005.

LOWY, Michael. A jaula de aço: Max Weber e o marxismo weberiano. São Paulo: Boitempo, 2014.

LÖWY, Michael. As aventuras de Karl Marx contra o Barão de Münchhausen: marxismo e positivismo na sociologia do conhecimento. São Paulo: Busca Vida, 1987.

LOWY, Michael. Crise ecologica, crise capitalista, crise de civilização: a alternativa ecossocialista. Cad. CRH, Salvador, v. 26, n. 67, p. 79-86, Apr. 2013. Disponível em 
http://www.scielo.br/scielo.php?script=sci_arttext\&pid=S0103-

$49792013000100006 \& \operatorname{lng}=$ en\&nrm=iso. Acesso em 08 de fevereiro de 2020.

MARTIN, Juan Carlos Gimeno, MADROÑAL, Angeles, Castaño. Antropologia comprometida, Antropologia de orientação pública e descolonialidade: desafios etnográficos e descolonização das metdologias. OPSIS (Online), Catalão, GO, v. 16, n. 2, p. 262 - 279, jul/dez 2016. Disponível em https://www.revistas.ufg.br/Opsis/article/view/37084. Acesso em 23 de fevereiro de 2020.

MANUEL, Antonio. La huella morisca. El Al-Ándalus que llevamos dentro. Almuzara: Córdoba, 2010.

SANTOS, Boaventura de Sousa. Construindo as Epistemologias do Sul. Antologia Esencial. 1.ed. Ciudad Autónoma de Buenos Aires: CLACSO, 2018a. v. 1.

SANTOS, Boaventura de Sousa. Na oficina do sociólogo artesão: aulas 2011 - 2016. São Paulo: Cortez, 2018b.

SANTOS, Boaventura de Sousa. Na oficina do sociólogo artesão. Aulas 2011-2016. São Paulo: Cortez, 2018.

SANTOS, Boaventura de Sousa. Para além do Pensamento Abissal: das linhas globais a uma ecologia de saberes. Revista crítica de Ciências Sociais. v. 78. Outubro, 2007. p. 3 - 46.

SANTOS, Boaventura de Sousa. Para uma sociologia das ausências e uma sociologia das emergências. Revista Crítica de Ciências Sociais. v. 63, 2002. p. 237 - 80.

SANTOS, Boaventura de Sousa. Um discurso sobre as ciências. São Paulo: Cortez, 2008.

SILVESTRE, Célia Maria Foster, LIMA, Marta. 2017. (22f). Relatório de pesquisa apresentado à Pró-reitoria de pesquisa e pós-graduação (PROPP). Iniciação científica. Amambai. UEMS, 2017.

SILVESTRE, Célia Maria Foster, VILLAFAN VIERA, Ana Janet. Gênero, etnia e acesso ao ensino superior: redimensionando a noção de projeto. MovimentAção, Dourados, v. 3, nº .5 , p. 88-105, 2016. Disponível em: http://ojs.ufgd.edu.br/index.php/movimentacao. Acesso em 08 de fevereiro de 2018. 